\title{
Critical Stresses in Materials with Cracks
}

\author{
SIMONA EUGENIA MANEA*, VALI IFIGENIA NICOLOF², TEODOR SIMA \\ ${ }^{1}$ Horia Hulubei National Institute for R\&D in Physics and Nuclear Engineering, 30 Reactorului Str., 077125, Bucharest-Magurele, \\ Ilfov, 077125, Romania \\ ${ }^{2}$ Technical College Carol I, 52 Porumbacu Str., 060366, Bucharest, Romania \\ 3University of Politehnica Bucharest, 313 Splaiul Independentei, 060042, Bucharest, Romania
}

\begin{abstract}
The fracture mechanics concepts, as well as the concepts introduced on the basis of principle of critical energy, correlated with strength of materials with cracks is analysed. The equivalent stress method of strength was applied to cracked materials, by using the concept of local critical stress. This one depends on the material behavior and the deterioration due to crack. Experimental results have been obtained with specimens of OL304 steel with different cracks. The influence of crack depth and crack width is put into evidence.
\end{abstract}

Keywords: crack, critical stress, deterioration, principle of critical energy, equivalent stress

From the very manufacturing stage, mechanical structures often feature micro-cracks or small cracks whose dimension may become critical when the structure is under operating conditions.

This raises the problem of determining whether a crack at any given time is dangerous to the structure.

a. In the literature, one can find expressions for stress at the tip of the crack and for stress at a certain distance from the crack tip [1;2]. On this basis, new concepts, correlated with the crack dimensions, which provide the ground for the chapter of fracture mechanics, have been defined, namely [3; 4]:

- stress intensity factor, for materials with linear-elastic behavior at the crack tip

$$
\left.\begin{array}{l}
K_{\mathrm{I}}=\sigma \cdot F \cdot \sqrt{\pi \cdot a} \cdot f_{\mathrm{I}}(r ; \theta) ; \\
K_{\text {IIIII }}=\tau_{\text {IIIII II }} \cdot F \cdot \sqrt{\pi \cdot a} \cdot f_{\text {II, II }}(r ; \theta)
\end{array}\right\}
$$

where I, II, III refers to the three mode of fracture (I opening; II sliding; III tearing); $\sigma$ normal stress, perpendicular to the crack of length $2 a ; \tau_{\text {.. }}(r ; \theta)$ - shear stress in the case of sliding (II) and tearing (III) mode, respectively; $F$ is a function of the crack geometry; $f_{\|}(r ; \theta), f_{\| I}(r ; \theta)$ - function which depend on the point coordinates, where the stress is calculated;

- crack tip opening displacement (CTOD) is used in the case of plastic deformation at the tip of the crack,

$$
\delta_{i}=f_{i}\left(\sigma ; a ; \sigma_{y} ; \varepsilon_{y}\right) \text {, }
$$

where $i=\mathrm{I}$, II or III, $\delta$ depends on the applied stress, $\sigma$, and on the yield properties of the material in the yield zone at the crack tip ( $\sigma_{-}$-yield stress; $\varepsilon$ - yield strain);

$J$ integral, expresses the decrease of the energy capable of deforming the material with a non-linear behavior, depending on the length with which the crack advances,

$$
J=-\frac{\partial E_{d}}{\partial a},
$$

where $E_{d}$ is the potential deformation energy per unit of body thickness.

In order to determine whether a particular crack is dangerous, in case the mechanical structure undergoes a certain static stress, specimens were standardized to experimentally determine the critical values of these concepts, namely:
$\mathrm{K}_{\mathrm{rc}}=\mathrm{K}_{\text {- }}$ - the fracture toughness in the case of stress intensity fáctor; $\delta_{i, c f}=\delta_{i, c}$ - the critical value of $\delta_{i} ; J_{i, c r}=J_{i, c}$ the critical value of J infegral.

In fracture mechanics, the condition that the loading of a mechanical structure with cracks should be admissible is expressed in one of the following relationships:

$$
K_{i} \leq K_{i, a i} \text {, }
$$

where $k_{i, a l}=k_{i, c r} / C_{k}$ is the allowable value of the stress intensity'factor; ; $C_{k}>$ - safety coefficient;

$$
\delta_{i} \leq \delta_{i, a l} \text {, }
$$

where $\delta_{i, a l}=\delta_{i, c r} / c_{\delta}$ is the allowable value of CTOD and $c_{\delta}$ $>1$ - safety coefficient;

$$
J_{i} \leq J_{i a i},
$$

where $J_{i, a}=J^{i, c r} / c$ is the allowable value of $J$ - integral and $c>1$ - saffety coefficient.

b. V.V. Jinescu [5] proposed a new philosophy for the calculation of mechanical structures with cracks, different from the one in fracture mechanics.

- In the case of static loading, based on the principle of critical energy, one calculates the total participation of the specific energy $P_{T}(t)$ determined by the local load, which is compared to the critical participation $P(t)$; the latter includes the influence of the crack [5-8]. Both variables are dimensionless and generally time-dependent $(\mathrm{t})$.

The total participation of specific energies at a given moment thas the expression [5],

$$
P_{T}(t)=\sum_{i}\left(\frac{\sigma_{i}}{\sigma_{i, r}}\right)^{\alpha+1} \cdot \delta_{\sigma_{i}},
$$

where $\sigma_{\mathrm{i}}$ is the applied stress; $\sigma_{\mathrm{i} f}$ - the critical value of $\sigma_{\mathrm{i}}$; $\delta_{\sigma i}=1$ if $\sigma_{i}$ acts in the direction of the deformation process; $\delta_{\sigma i}^{\sigma i}=0$ if $\sigma_{i}$ has no influence and $\delta_{\sigma i}=-1$ if $\sigma_{i}$ opposes the deformation process.

The exponent depends on the behavior of the material expressed by the power law,

$$
\sigma=M_{\sigma} \cdot \varepsilon^{k},
$$

where $\sigma$ is the applied stress; $\varepsilon$ - strain; $M_{\sigma^{\prime}}$ k - constants.

The critical participation at time $t$, when critical stresses are deterministic variables, has the expression,

$$
P_{c r}(t)=1-D(t) \text {, }
$$

\footnotetext{
*email: smanea@nipne.ro, Phone: 0730529860
} 
where $\mathrm{D}(\mathrm{t})$ is the deterioration at time $t$.

If the crack increases over time, deterioration will also increase. Critical participation depends on the value of the deterioration which may be calculated with the existing relationships in the literature [9-11].

In work [25], the deterioration was correlated with the dimensions of the crack by applying fracture mechanics concepts, namely,

$$
D(a ; c)=\left(\frac{K_{\mathrm{I}}}{K_{\mathrm{Ic}}}\right)^{2}
$$

or,

$$
D(a, c)=\left(\frac{\delta_{\mathrm{I}}}{\delta_{\mathrm{Ic}}}\right)^{k+1},
$$

where exponent $k$ is derived from the law of behavior (8).

The influence of the crack is included in the strength calculation based on the principle of critical energy, without the need for the experimental determination of new material characteristics, as is the case with fracture mechanics.

This method of calculating the strength of cracked mechanical structures has been applied to many cases of mechanical stresses [5-8; 11-18]. The superposition of loads of the same nature or of a different nature proved to be possible only on the basis of the relations obtained through the use of the principle of critical energy [19-30].

c. In a second step, one moved from the calculation based on the participation of specific energy induced by the loads, to the classical calculation based on the concept of equivalent stress, $\sigma$. In this case the influence of the crack was introduced into the expression of critical stress, $\sigma_{\mathrm{cr}} \mathrm{D}$ which depends on deterioration $\mathrm{D}$.

V.V. J inescu and V.-I. Nicolof [13] proposed the following relationship for the local critical stress of the structure with cracks,

$$
\sigma_{c r}(D)=\sigma_{c r} \cdot[1-D(a ; c)]^{\frac{1}{a t}},
$$

where $D=D(a ; c)$ is the deterioration caused by a crack with depth $a$ and length $2 c$, and $\sigma_{c r}$ is the critical stress of the material without crack.

Instead of the concepts of fracture mechanics, one uses the concept of local critical stress of the mechanical structure with cracks. With this concept it has become possible to use strength theories based on the equivalent stress concept. The condition for a cracked structure to undergo admissible loads is - structurally - identical with the strength of materials condition,

$$
\sigma_{\varepsilon q} \leq \sigma_{a:}(D),
$$

where $\sigma$ is calculated on the basis of the main stresses loading the structures, without taking into account the crack, and the local admissible stress (in the crack area) is calculated with the relation,

$$
\sigma_{a i}(D)=\frac{\sigma_{c r}(D)}{c_{D}},
$$

where $c_{P}>1$ is the safety coefficient.

In order to use relationship (11) for checking a cracked mechanical structure, it is necessary to know the interdependence between $\sigma_{c r}(D)$ and the deterioration $D$ produced by the crack.

In the papers [31-33], relationships have been proposed for yield loading in tubular cylindrical specimens with cracks, which may be written as in equation, obtained in [13],

$$
Y_{y}(D)=Y_{y} \cdot[1-D(a ; c)]^{\frac{1}{a t}},
$$

where $Y(D)$ is the limit load of the cracked tubular specimen; $Y$ is the limit load of the crackless tubular specimen and $\alpha=0$.

\section{Local critical stresses and loads in mechanical structures with cracks}

a. From previous research, one has found that the local critical stress or load decreases with an increase in the crack depth, a, length $2 c$ or angular opening $2 \theta$. For example, with hollow tubular specimens with semielliptical crack at the inner surface (fig $1, a, b$ ) under axial force $F$, processing [14] the data from [34] the dependence of $\sigma(a ; \theta) / \sigma_{c r}$ were obtained as a function of a/s for three values of reported angle $\theta / \pi$ (fig. 2). The behavior of the pipe material has been considered as ideally-plastic, i.e. the maximum stress $\sigma_{c r}=\sigma_{Y}$ is the yield stress.

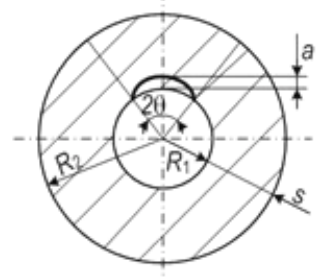

a.

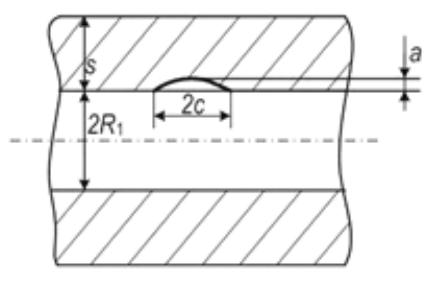

Fig. 1. Tubular sample with circumferential (a) and axial (b) semielliptical crack on the inner surface.

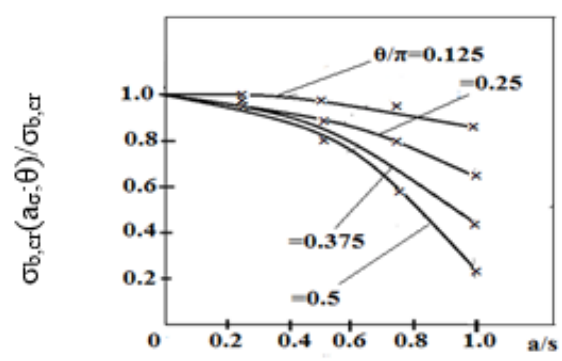

Fig. 2. The dependence of reported critical stress $\frac{\sigma_{c r}(a ; \theta)}{\sigma_{c r}}$ on

ratio $a / s$, for three values of $\theta / \pi$ for tubular specimen represented in figure $1, a$, under axial force, namely axial stress, $\sigma$

Higher $a / s$ and $\theta / \pi$, lover the critical stress $\sigma(a ; \theta)$. $b$. The influence of the crack width has not been considered in research carried so far. We shall further present the influence of the crack on the fracture strength of some OL 304 ( $5 \mathrm{NiCr} 180)$ steel specimens, used in the construction of equipment in the chemical, pharmaceutical, petroleum, nuclear, food industries.

Rectangular section specimens (fig. 3) have been created with cracks of $2 c=5$ or $10 \mathrm{~mm}$, unpenetrated $(a=1 \mathrm{~mm})$ or penetrated $a=2 \mathrm{~mm}$, perpendicular to the direction of loading $\left(\beta=90^{\circ}\right)$ or inclined $\left(\beta=45^{\circ}\right)$.

Cracks with width e were obtained by electro-erosion, which allowed for cracks with clean edges and crack depth control. The crack widths were $e=0.3 ; 0.4 ; 0.6 ; 0.8$ and 0.9 .

The experiments were performed on a universal test machine A900 (TC100), LGB Testing Equipment, connected to a computer equipped with the LBG Easy Test software.

- Unpenetrated specimens of OL304 were used to determine the behavior of the tested steel. 


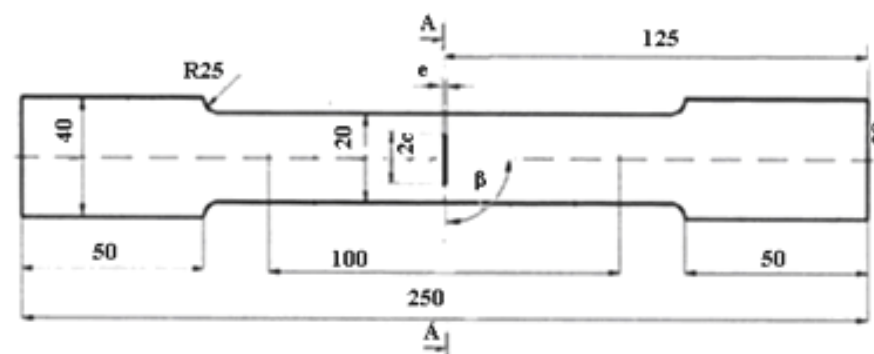

Based on the graphical representation of the interdependence between natural stress $\sigma_{n}$ and naturalstrain, $\varepsilon_{n}$, the exponentk from relation (8) was calculated. Figure 4 shows the dependence between natural concepts $\sigma_{n}\left(\varepsilon_{n}\right)$ and engineering concepts $\sigma(\varepsilon)$.

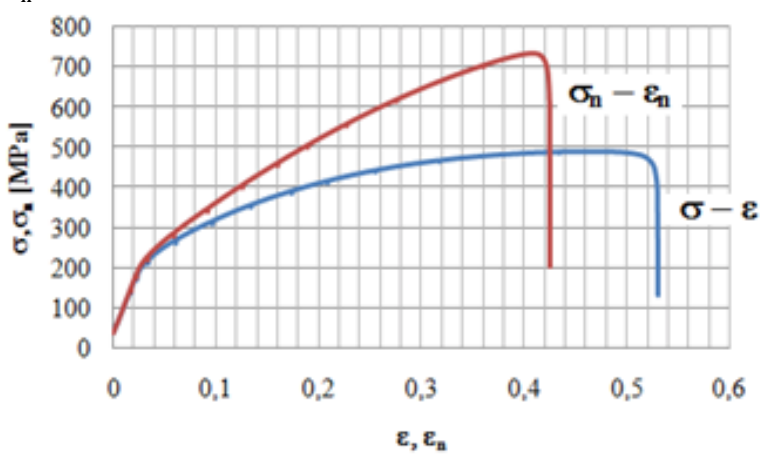

Fig. 4. Dependencies $\sigma_{n}=\varepsilon_{n}$ and $\sigma-\varepsilon$ for an OL304 steel specimen without cracks under traction load

In this case, the result was exponent $\mathrm{k}=0.205$.

-For an OL304 specimen with unpenetrated crack, $(a=1 \mathrm{~mm})$, featuring $2 c=5 \mathrm{~mm}$, and $\beta=90^{\circ}$ and $e=0.8$ $\mathrm{mm}$, under traction load, dependencies $\sigma_{n}{ }^{-} \varepsilon_{n}$ and $\sigma-\varepsilon$ have been shown in figure 5 .

It has been found that the ultimate stress of the cracked specimen is much smaller than the one in the uncracked specimen.

By increasing the crack width, $e$, the ultimate stress decreases.
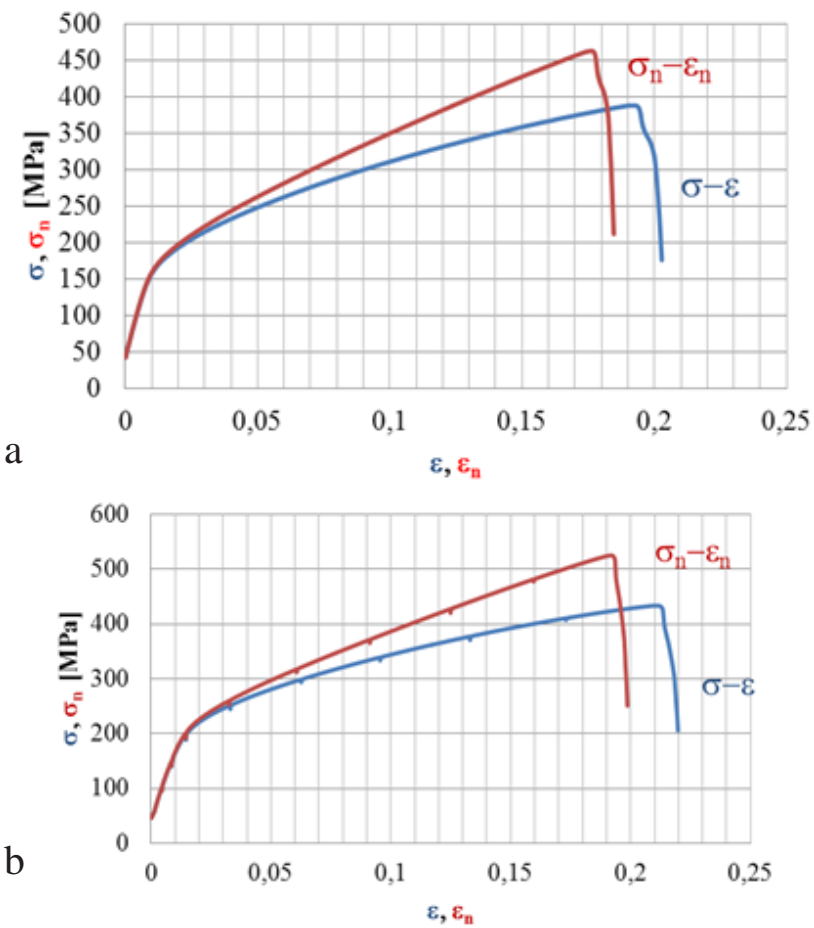

Fig. 5. Dependencies $\sigma_{n}-\varepsilon_{n}$ and $\sigma-\varepsilon$ for OL 304 specimens with unpenetrated crack $(a=1 \mathrm{~mm}$ ) featuring: $\mathrm{a}-2 \mathrm{c}=5 \mathrm{mme}=0.8 \mathrm{~mm}$ and $\beta=90^{\circ} ; b-2 c=10 \mathrm{~mm} ; e=0.6 \mathrm{~mm}$ and $\beta=45^{\circ}$

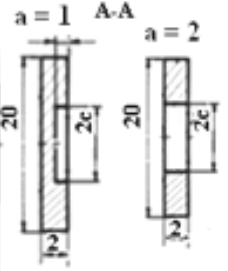

Fig. 3. Rectangular section specimens with an impenetrable (a) or through crack (b), inclined at or inclined at $\beta=90^{\circ}$ or inclined at $45^{\circ}$.

The ultimate stress $\sigma_{u n}$ and $\sigma_{\mu}$, respectively, of the specimen with unpenetrated crack diminishes with the enlargement of crack width e (fig. 6), both when $2 c=5 \mathrm{~mm}$ and $\beta=90^{\circ}$ as well as in the case when $2 c=10 \mathrm{~mm}$ and $\beta=45^{\circ}$.

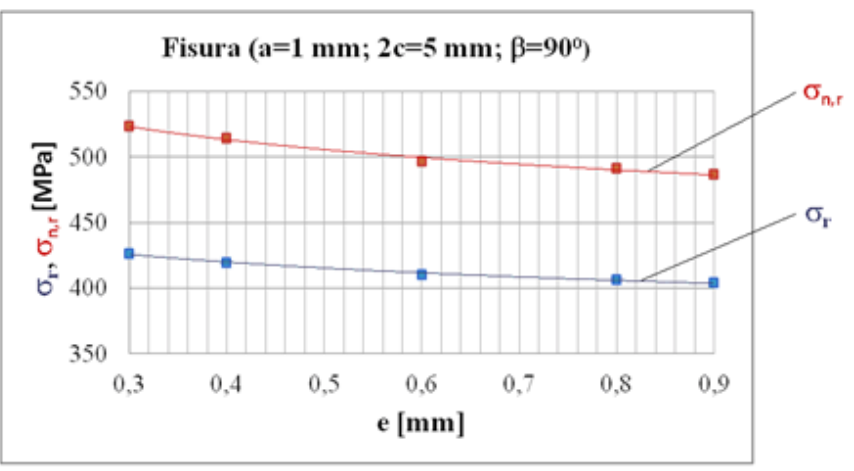

a.

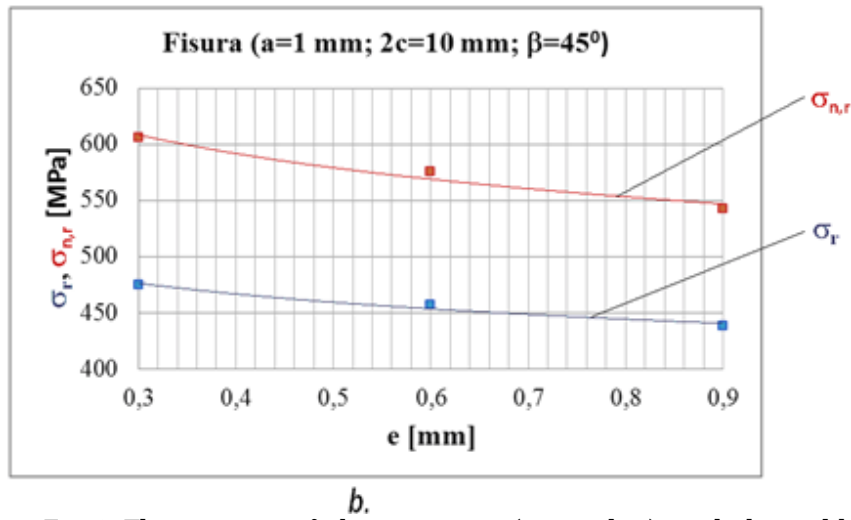

Fig. 6. The variation of ultimate stress $\left(\sigma_{u n}\right.$ and $\left.\sigma_{r}\right)$ with the width of the crack $e$, in the case $2 c=5 \mathrm{~mm}$ and $\beta=90^{\circ}(a)$, and if $2 c=10 \mathrm{~mm}$ and $\beta=45^{\circ}(b)$

-In the case of OL 304 specimens with the penetrating crack $(a=2 \mathrm{~mm})$ under traction load there have been obtained the dependencies required for traction, the dependencies represented in figure 7 for cracks with $\beta=90^{\circ}$ and $2 c=5 \mathrm{~mm}, e=0.6 \mathrm{~mm}$ (fig. $7, a$ ) and $2 c=10 \mathrm{~mm}$, $\mathrm{e}=0.3 \mathrm{~mm}$ (fig.7, b). It is noted that with an increasing crack length the fracture strength decreases.

The dependence of the fracture strength on the crack width is shown in figure 8 , which also demonstrates the influence of the crack length. For $2 c=5 \mathrm{~mm}$ the values of the fracture strength (fig.8, a) are higher than when $2 \mathrm{c}=10 \mathrm{~mm} \quad$ (fig.8, b).

Since the crack width influences the fracture strength, in general, the expression of the critical stress (here the ultimate stress) as well as the critical load will be written as follows,

$$
\begin{aligned}
& \sigma_{c r}(a ; c ; e ; \beta)=\sigma_{c r} \cdot[1-D(a ; c ; e ; \beta)] \frac{1}{\alpha+1} \\
& \left.Y_{c r}(a ; c ; e ; \beta)=Y_{c r} \cdot[1-D(a ; c ; e ; \beta)]\right]^{\frac{1}{\alpha+1}}
\end{aligned}
$$




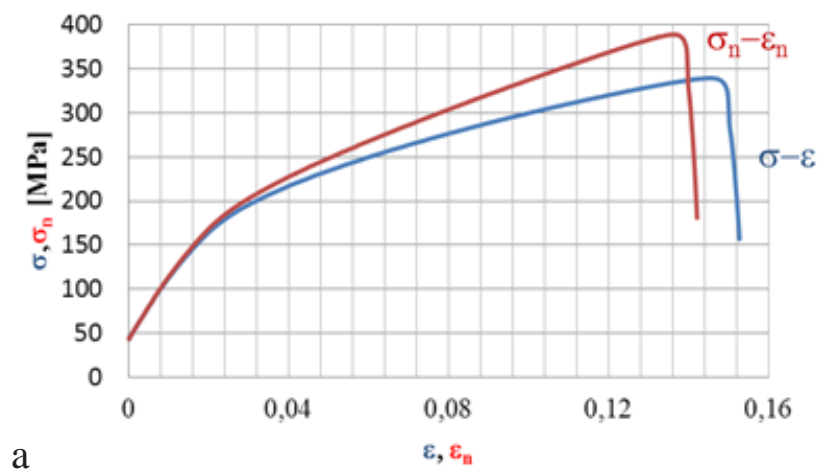

a

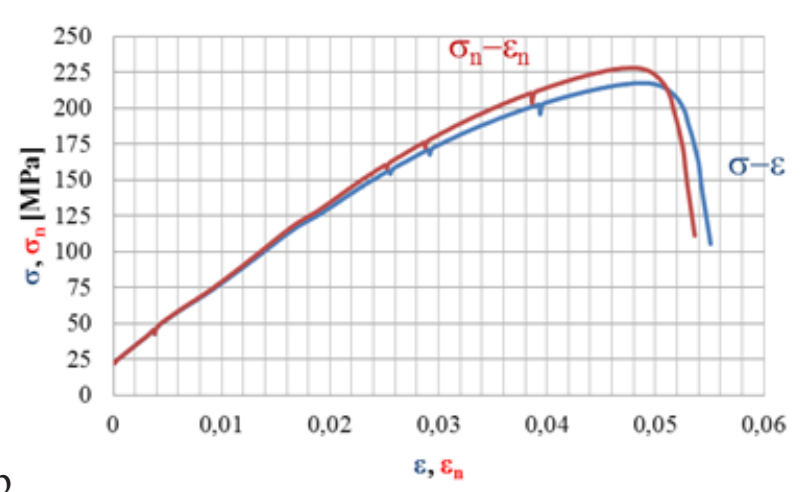

Fig.7. Diagrammes $\sigma_{n}-\varepsilon_{n}$ and $\sigma-\varepsilon$ for OL 304 specimens with penetrating $\operatorname{crack}(a=2 \mathrm{~mm}), \beta=90^{\circ}$ and: $a-2 c=5 \mathrm{~mm}$; $e=0.6 \mathrm{~mm} ; b-2 c=10 \mathrm{~mm}$ and $e=0.3 \mathrm{~mm}$

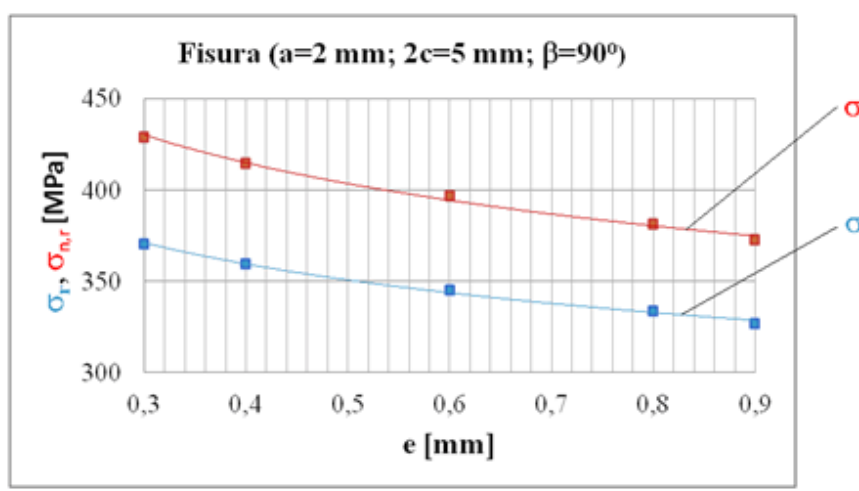

a.

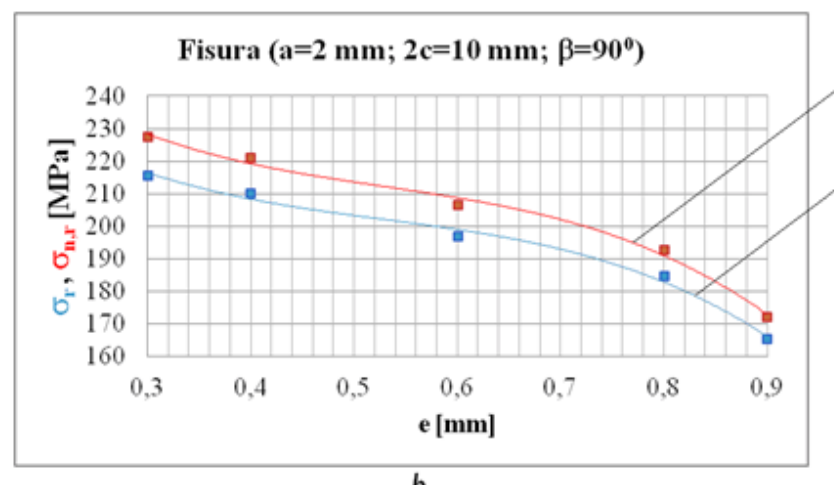

$b$.

Fig. 8. The variation in fracture strength $\left(\sigma_{r, n}\right.$ and $\left.\sigma_{r}\right)$ dependent on the crack width (e) for OL 304 specimens with crack length $2 \mathrm{c}=5 \mathrm{~mm}(\mathrm{a})$ and $2 \mathrm{c}=10 \mathrm{~mm}(\mathrm{~b})$.

where one has emphasized the findings from the experiments performed and presented in the foregoing figures, that the critical parameters depend both on the configuration of the crack $(a ; c ; e)$ and on its inclination.

\section{Conclusions}

The paper elaborates on the approach to the problem of material fracture by resorting to the concepts based on the principle of critical energy, namely:

- comparison of the total participation of the specific energies corresponding to the loadings, to the critical participation, dependent on crack induced deterioration;

- comparison of the equivalent stresses corresponding to the stresses loading the structure, to the local critical stress dependent on the crack configuration and inclination.

The experiments performed on OL 304 specimens have shown that the evaluation of the material fracture may be made more easily by resorting to the proposed concepts than with those currently used in fracture mechanics.

\section{References}

1.IRWIN G.R., Analysis of Stresses and Strain near the End of a Crack Traversing a Plate, ASME J ournal of Applied Mechanics, vol. 24, 1957. 2.HARVEY J .F., Theory and Design of Pressure Vessels, Second Edition, Reinhold Comp., New York, 1974.

3.CIOCLOV D.D., Mecanica ruperii materialelor, Editura Academiei, Bucuresti, 1997.

4.PANA T., PASTRAMA S.-D., Integritatea structurilor mecanice, editura Fair Parteners, Bucuresti, 2000.

5.JINESCU V.V., Energonica, Editura Semne, Bucuresti, 1997.

6.J INESCU V.V., Principiul energiei critice si aplicatiile sale, Editura Academiei Romane, Bucuresti, 2005.

7.J INESCU V.V., Tratat de Termomecanica, vol. 1, Editura AGIR, Bucuresti, 2011.

8. INESCU V.V., Applications in Mechanical Engineering of the Principle of Critical Energy, Lambert Academic Publishing, Saarbrücken, 2015. 9.FATEMI A., YANG L., Cumulative Fatigue Damage and Life Prediction Theories: A survey of the State of the Art for Homogeneous Materials, Int. J. Fatigue, 20, 1998, pp. 9-34.

10.J INESCU V.V., Cumulation of Effects in calculation the Deterioration of Fatigue loaded Structures, International J. Damage Mech., 21, July, 2012, p. 671-695.

11.J INESCU V.V., Critical Energy Approach for the Fatigue life Calculation under Blocks with different normal Stress Amplitudes, Int. J. Mechanical Sci., 67, febr. 2013, p. 78-88.

12.IORDACHESCU (NICOLOF), V.I., Cercetari asupra rezistentei structurilor mecanice cu fisuri, cu aplicatie la echipamentele sub presiune, Phd. thesis, Universitatea Politehnica din Bucuresti, 2013. 13.J INESCU V.V., IORDÃCHESCU V.I., Calculation of deterioration due to cracks in tubular specimens, U.P.B. Sci.Bull., Series D, 76, 2014, p. $\sigma_{\mathrm{n}, \mathrm{r}} 149-160$.

14. I INESCU V.V., NICOLOF V.I., CHELU A., MANEA S.E., Critical stresses, critical group of stresses and strength of tubular structures without and with cracks, U.P.B. Sci.Bull., Series D, 77, 2015 p. 165-176.

15.J INESCU V.V., CHELU A., TEODORESCU N., NICOLOF V.I., Strength of tubular samples and tubular cracked junctions under combined loads, Rev. Chim. (Bucharest), 66, no. 11, 2015, p. 1832-1836.

16.J INESCU V.V., NICO LOF V.-I., TEODORESCU N., Effects superposition under imposed deterioration and simultaneous fatigue in different regimes, Int. J. Damage Mech, 26, Issue 5, July 2017, p. 633-650. 17.JINESCU V.V., The Principle of Critical Energy, Consequences and Applications, Proceedings of the Romanian Academy, Series A, 14, no. 2, 2013, p. 152-160.

18.J INESCU V.V., Fatigue life prediction for simultaneous cyclic loading with blocks of normal stresses and shear stresses, J. of Eng. Sci. and Innovation, 1, no. 1, 2016, p. 1-16.

19. INESCU V.V., IORDACHESCU V.-I., TEODORESCU N., Relation for Calculation of Critical Stresses in Pressure Equipment with Cracks, Rev. Chim. (Bucharest), 64, no. 8, 2013, p. 858-863.

20.J INESCU V.V., Fatigue Life of the Process Equipment Made of Nonlinear Materials, Rev. Chim. (Bucharest), 63, no. 1, 2012, p. 98101. 
21.J INESCU, V.V., MANEA, S.-E., JINESCU, G., NICOLOF, V.-I., Superposition of potential chemical polluants and radioisotopes and their influence upon environment and living organismes, Rev. Chim. (Bucharest), 68, no. 9, 2017, p. 2189

22.J INESCU V.V., NICOLOF V.-I., JINESCU C., CHELU A., Superposition of Effects in Calculating the Deterioration of Tubular Structures and in Non-newtonian Fluid Flow, Rev. Chim. (Bucharest), 66, no. 5, 2015, p. $698-702$.

23.NICOLOF, V.-I., SIMA, T., Design of pressure equipment taking into account the cracks, Rev. Chim. (Bucharest), 66, no. 2, 2015, p. 271276.

24.J INESCU V.V., MANEA S.-E., JINESCU C., The result of loads superposition upon the matter and particularity upon the environment, Rev. Chim. (Bucharest), 68, no. 4, 2017, p. 656-665.

25.JINESCU, V.V., NICOLOF, V.-I., Strength criteria at the tip of the crack, Eng. Fracture Mech., 142, 2015, p. 108-115.

26.J INESCU, V.V., JINESCU, G., Durata de viata a structurilor tehnice si a organismelor vii, Editura TEHNICA-INFO, Chisinau, 2018.

27.JINESCU, V.V., The Energy Concept in Critical Group of Loads Calculation, Int. J. of Press. Vess. and Piping, 38, no. 3, 1989, p. 211226.
28.CHELU A., Cercetari privitoare la suprapunerea efectelor solicitarilor si deteriorãrii produsa de fisuri asupra structurilor mecanice, cu aplicatie la joncpunile tubulare ale echipamentelor sub presiune, Phd. thesis, Universitatea Politehnica din Bucuresti, 2015.

29. INESCU V.V., NICOLOF V.-I., CHELU A., MANEA S.-E., Calculation of the local critical state taking into account the deterioration and the residual stresses, J. of Eng. Sci. and Innovation, 2, no. 3, 2017, p. 9-21. 30.J INESCU V.V., Stability Determination of Structure under Groups of Loads by Using the Principle of Critical Energy, Int. J of Press. Vess.and Piping, 48, no. 4, 1991, p. 343-375.

31.KIM Y-J, SHIM D-J, NIKBIN K., KIM Y-J, HWANG S-S, KIM J -S, Finite element based plastic limit loads for cylinders with part-through surface cracks under combined loading, Int. J. Press. Vess.\&Piping, 80, no. 7-8, 2003, p. 527.

32.KIM N-H, OH C-S, KIM Y-J, KIM J-S, JERNG DW, BUDDEN PJ, Limit loads and fracture mechanics parameters for thick-walled pipes, Int. J. Press. Vess. and Piping, 88, no. 10, 2011, p. 403.

33.OH C-S, SONG T-K, KIM Y-J, Approximate / estimates for axial partthrough surface cracked pipes, Fat. Fract. Eng. Mater. Struct., 30, no. 12, 2007, p. 1127.

34.YUN-J AE KIM, DO-JUN SHIM, KAMRAN NIKBIN, YOUNG-JIN KIM, SEONG-SIK HWAN, JOUNG-SOO KIM, Finite element based plastic limit loads for cylinders with part-through surface cracks under combined loading, Int. J. Press. Vess. and Piping, 80, 2003, p. 527-540.

Manuscript received: 18.07 .2018 